\title{
Epidemiological, Pathophysiological and Clinical Peculiarities of Graves' Disease in Children with Down and Turner Syndrome: A Literature Review
}

\author{
Malgorzata Wasniewska, Tommaso Aversa, Filippo De Luca*, Mariella Valenzise, \\ Maria Francesca Messina, Fortunato Lombardo
}

Department of Pediatrics, University of Messina, Messina, Italy

Email: ${ }^{\text {filippo.deluca@unime.it }}$

Received 30 April 2014; revised 4 June 2014; accepted 14 June 2014

Copyright (C) 2014 by authors and Scientific Research Publishing Inc.

This work is licensed under the Creative Commons Attribution International License (CC BY).

http://creativecommons.org/licenses/by/4.0/

(c) O) Open Access

\begin{abstract}
Aim: to describe the salient relationships between Graves' disease (GD) and both Turner syndrome (TS) and Down syndrome (DS). Design: to conduct a secondary analysis of current literature on this topic. Results: 1) the prevalences of GD in TS and in DS young patients are $1.7 \%$ and $6.5 \%$, respectively, i.e. higher than that in pediatric general population (around 1\%o); 2) in both these chromosomopathies GD presentation is often preceded by Hashimoto's thyroiditis (HT) antecedents; 3) in both TS and DS, GD presents with a clinical picture very similar to that observed in GD patients without these chromosomopathies; 4) in TS, clinical course of GD under pharmacological therapy is very similar to that observed in non-TS girls; 5) in DS, clinical course of GD under pharmacological therapy is less severe than that in non-DS patients. Conclusions: in the children with either TS or DS, GD is characterized by two common epidemiological peculiarities, i.e. increased prevalence rate and elevated frequency of HT antecedents.
\end{abstract}

\section{Keywords}

Autoimmune Thyroid Diseases, Chromosomopathies, Clinical Course, Hyperthyroidism, Prevalence

\section{Introduction}

Graves' disease (GD) is an organ-specific autoimmune disease, which represents the commonest cause of hy"Corresponding author.

How to cite this paper: Wasniewska, M., Aversa, T., De Luca, F., Valenzise, M., Messina, M.F. and Lombardo, F. (2014) Epidemiological, Pathophysiological and Clinical Peculiarities of Graves' Disease in Children with Down and Turner Syndrome: A Literature Review. Health, 6, 1447-1452. http://dx.doi.org/10.4236/health.2014.612178 
perthyroidism in childhood and adolescence (84\% of cases), followed by hashitoxicosis (12\% of cases) [1]. In pediatric age GD is a rare disease, whose prevalence has been estimated to fluctuate around 1\%o [2] and is distinctly lower than that reported for Hashimoto's thyroiditis (HT) in the same age bracket [3]. GD is more common in girls than that in boys and its frequency increases with age, peaking during adolescence. GD occurs more frequently in genetically susceptible children, as demonstrated by the higher concordance in monozygotic than dizygotic twins [4], but its occurrence is also conditioned by environmental triggers, such as iodine intake, smoking and immune modulators. Other important risk factors for GD are familial antecedents of autoimmune illnesses, link with other autoimmune diseases and association with Turner syndrome (TS) or Down syndrome (DS), i.e. two chromosomopathies which are known to be frequently linked with autoimmune disorders.

According to the most recent literature reports, GD in patients with either TS or DS seems to be characterized by some significant peculiarities, in terms of epidemiology, pathophysiology and clinical presentation and course. These reports seem to suggest that the association with these chromosopathies might condition a peculiar phenotypical expression of GD, thus shedding some new light on the pathophysiology of this autoimmune thyroid disease.

Aim of this review is to summarize, for the first time, the salient news concerning the relationship between GD and both these chromosopathies, in order to underline some common aspects which characterize phenoltypical expression of GD in both TS and DS.

\section{Epidemiology}

There is a consensus in the literature that autoimmune diseases are more frequent in girls with TS than in the pediatric general population [5]-[7] and that HT is the most frequent autoimmune disorder in TS [8] [9]. Considering the well-documented relationships between HT and GD, even GD might be expected to be more frequent in TS, but the epidemiological studies on the link between TS and GD are few and based on limited study populations [6] [8] [10].

According to the results of a recent report on the prevalence of GD in a series of 408 young patients with TS, the prevalence of GD in the pediatric TS population is 1.7\% [11], that is very similar to the one detected in the last ten years in other epidemiological investigations covering young TS cohorts: from $1.7 \%$ to $3.0 \%$ [8] [10] [12]. On the basis of these epidemiological data, we can infer that the prevalence rate of GD in TS is distinctly higher than that reported in the pediatric general population [2], but very far from that of HT in TS, which is generally reported to range from $10 \%$ to $21 \%$ [8] [12] [13]. However, it has to be considered that, even in the pediatric general population, there is a relevant discrepancy between the frequencies of HT and GD [14]. Another interesting inference of the recent epidemiological study by Valenzise et al. is that GD frequency in TS does not seem to be affected by karyotype [11], a finding that had been previously reported also by other Authors [12] [15] [16]. By contrast, according to other studies, autoimmune thyroid diseases seem to be particularly common in TS patients with X-isochromosome karyotype [8] [17]-[19].

Considering that DS patients are well-known to be more prone to develop both autoimmune diseases and thyroid disorders, GD would be expected to be more frequent even in this chromosomopathy [20]. This is also suggested by the few available epidemiological studies, which demonstrated in the past, on limited populations, a GD frequency in DS ranging from $0.5 \%$ to $2.9 \%$ [21]-[24], i.e. higher than in pediatric general population (around 1\%). According to the results of a more recent epidemiological study, aiming to assess the prevalence of GD in a population of 1832 DS patients, such prevalence has been well-established to be $6.5 \%$, with an estimated incidence of 43/10,000 per year, which is distinctly higher than that estimated in the general population [25].

\section{Pathophysiology}

Although it is well assessed, on the basis of the above epidemiological study results, that patients with TS and DS are more prone to develop GD and other autoimmune diseases, the pathophysiological mechanisms that underlie this predisposition have not been as yet clearly elucidated.

In TS it has been recently postulated that the increased risk of autoimmune thyroid disorders and other autoimmune diseases might be associated with haploinsufficiency of the genes in the pseudoautosomal region of X-chromosome [6] [26], which may play an important role in the pathogenesis of autoimmune disorders [13]. According to other Authors, the risk of developing thyroid autoimmunity is particularly high in women with 
$\mathrm{X}$-isochromosome, thus suggesting that a gene on the long arm of $\mathrm{X}$ chromosome might be involved in the pathogenesis of autoimmune thyroid illnesses [19]. In an our recent study on the relationships between TS and GD, however, we have found no correlation between patients' karyotype and GD risk and, therefore, our findings fail to support the hypothesis of a specific link between GD and the isochromosome Xq karyotype [11]. However, other characteristics of TS phenotype, such as an up-regulation of proinflammatory cytokines, might also be, at least partially, responsible for the increased risk [27].

In DS the increased susceptibility to autoimmune diseases has been recently attributed to the dysregulation of immune system [28]. The consequent defect of inhibitory activity may partially explain the elevated frequency of autoimmune disorders in this syndrome [29].

Another relevant pathophysiological peculiarity of GD in TS and DS is that, in young patients with these two chromosomopathies, GD presentation is often (26\% of cases) preceded by HT antecedents [30]. It was already known that, also in the general population, there exists a continuum between HT and GD, within the spectrum of autoimmune thyroid diseases [31]-[33]. A very recent study of our study group has shown, for the first time, that young patients with either TS or DS are more likely to progress from HT to GD [30]. Although the pathophysiological bases of these findings need to be clarified, our data suggest that the association with TS or DS might favor metamorphosis from HT to GD [30]. An immunological mechanism, which might account for a conversion from HT to GD, is alteration in the biological activity of thyroid receptor autoantibodies (TRABs), from thyroid blocking antibodies during the hypothyroid phase, to thyroid stimulating antibodies during the hyperthyroid phase [31]. However, this remains a controversial point, with no evidence that the shifting from one disorder to the other one really reflects changes in the biological activity of TRABs.

\section{Clinical Presentation}

Studies on clinical aspects of GD in young patients with either TS or DS are very few [11] [25] [34] and based on limited cohorts, due to the rarity of this disease, which is, in absolute, distinctly more infrequent than HT [2] [3].

According to the only available study aiming to compare GD presentation and evolution under treatment in two different cohorts of girls with or without TS, GD in TS girls presents significantly later than in those without TS [11]. This is not surprising, considering that the prevalence of autoimmune thyroid diseases in TS has been reported to increase with age and to double from the first to the third decade of life [5] [8]. Another peculiarity of GD, in TS patients, is the more frequent association with other autoimmune disorders [11], which confirms that TS girls are at higher risk for developing autoimmune disorders, with respect to the girls without TS [5]-[7]. Finally, a further peculiar aspect observed in TS girls is that, at GD presentation, these patients exhibit significantly lower FT4 serum levels [11]. A likely explanation for this finding may be that GD diagnosis in TS patients is established at an earlier phase, as they were already under special control and periodically monitored [11].

In DS patients GD presentation occurs at a younger age and does not demonstrate any gender predominance against that observed in patients without DS [34]. From a clinical point of view, GD patients with DS present with a picture that is not significantly different from the one observed in a control GD population without DS, as suggested by the similar frequencies of both ophthalmopathy and other clinical manifestations found in the two series of patients [34]. Moreover, even FT4 and TRAB serum levels at GD diagnosis are very close in DS and control groups [34]. In DS the same clinical and biochemical peculiarities at presentation of GD had already been described by Goday-Arno et al., in an another study aiming to assess prevalence and clinical features of GD in a population with DS attending a specialized medical center [25]. Sometimes GD in DS may present in the context of a very complex and severe polyendocrine autoimmune picture [35].

\section{Clinical Course under Therapy}

Clinical evolution under methimazole treatment has been recently evaluated in two studies aiming to ascertain whether GD patients with either TS or DS may exhibit a different response to pharmacological therapy, when compared with patients without these chromosomopathies [11] [34].

In TS series both the initial methimazole dosage and that needed to maintain biochemical euthyroidism during the first cycle of therapy were very similar to those employed in the girls without TS [11]. Median times for relapse after the first cycle withdrawal were superimposable in TS cohort and in control group. Remission rates 
during the first cycle of methimazole, relapse rates after the first cycle withdrawal (Table 1) and cumulative incidences of relapse were not significantly different in the two groups. After the first one, further cycles of methimazole treatment were needed in 3/7 girls with TS and in 26/89 without TS, with no statistically relevant differences [34]. Non-pharmacological therapies, such as surgery or radioiodine ablation, were needed in only one girl with TS and in 10/89 without TS (Table 1). At the time of the last examination the percentages of girls showing a "definitive" remission, as defined in Table 1, were not statistically different in the two groups with GD (Table 1).

On the basis of the above results it was concluded that, in GD girls with TS, clinical course under treatment is very similar to the one observed in GD girls without TS [11].

In DS patients the initial methimazole dosage was very similar to that employed in GD controls, whereas the average dosage needed to maintain euthyroidism during the first cycle of treatment was significantly lower [34]. Median times for relapse were similar in the two groups, but relapse rates after the first cycle withdrawal and cumulative incidence of relapse were significantly lower in DS patients [34]. Persistent remission rates after at least two years of methimazole therapy were significantly higher in DS patients (Table 1). Non-pharmacological therapies were needed in no patients with DS (Table 1). At the last examination, the percentages of patients exhibiting a definitive remission, as defined in Table 1, was not significantly different in the two groups [34].

At the light of these results, it was concluded that clinical course of GD under pharmacological therapy is less severe in GD patients with DS than in those without DS. Such inference is in contrast with that of Goday-Arno et al. [25]. In that study, in fact, no DS patients achieved remission longer than six months under pharmacological treatment and almost all of them needed radioiodine therapy [25].

\section{Results}

1) The prevalence of GD in TS and in DS young patients are 1.7\% and 6.5\%, respectively, i.e. higher than in pediatric general population (around 1\%);

2) In both these chromosomopathies GD presentation is often preceded by HT antecedents;

3) In both TS and DS, GD presents with a clinical picture very similar to that observed in GD patients without these chromosomopathies;

4) In TS clinical course of GD under pharmacological therapy is very similar to that observed in non-TS girls;

5) In DS clinical course of GD under pharmacological therapy is less severe than in non-DS patients.

\section{Conclusion}

In the children with either TS or DS, GD is characterized by two common epidemiological peculiarities, i.e. in-

Table 1. Initial remission rates ${ }^{*}$, relapse rates $^{* *}$, persistent remission rates ${ }^{* * *}$, non-pharmacological therapy rates ${ }^{\circ}$ and definitive remission rates ${ }^{\circ}$ in the patients with Turner syndrome (TS), in those with Down syndrome (DS) and in the respective control groups with Graves’ disease but without TS and DS (from references nos. 11 and 34 of this report).

\begin{tabular}{cccccc}
\hline Patients & $\begin{array}{c}\text { Initial remission } \\
\text { rates (\%) }\end{array}$ & $\begin{array}{c}\text { Relapse } \\
\text { Rates (\%) }\end{array}$ & $\begin{array}{c}\text { Persistent remission } \\
\text { rates (\%) }\end{array}$ & $\begin{array}{c}\text { Non-pharmacological } \\
\text { therapy rates (\%) }\end{array}$ & $\begin{array}{c}\text { Definitive remission } \\
\text { rates (\%) }\end{array}$ \\
\hline $\begin{array}{c}\text { TS girls (n= 7) } \\
\begin{array}{c}\text { Non-TS girls } \\
\text { (n = 89) }\end{array}\end{array}$ & 85.7 & 42.8 & 57.1 & 14.3 & 71.4 \\
$\chi^{2}$ & 52.8 & 29.2 & 27.0 & 11.2 & 38.2 \\
p & 0.90 & 0.003 & 2.9 & 0.06 & 2.9 \\
$\begin{array}{c}\text { DS patients } \\
\text { (n = 28) }\end{array}$ & n.s. & n.s. & n.s. & n.s. & n.s. \\
$\begin{array}{c}\text { Non-DS patients } \\
\text { (n= 109) }\end{array}$ & 53.6 & 7.1 & 46.4 & 0 & 46.4 \\
$\chi^{2}$ & 54.1 & 31.2 & 26.7 & 11.0 & 37.7 \\
p & 0.003 & 7.4 & 4.1 & 3.8 & 0.75 \\
\hline
\end{tabular}

${ }^{*}$ Under the $1^{\text {st }}$ cycle of methimazole; ${ }^{* *}$ After the $1^{\text {st }}$ methimazole cycle withdrawal; ${ }^{* * *}$ Persistent for at least 2 yrs after the last methimazole cycle withdrawal; ${ }^{\circ}$ Percentages of the patients who underwent either surgery or radioiodine ablation; ${ }^{\circ}$ Percentages of the patients with persistent postpharmacological remission plus those who underwent non-pharmacological therapies. 
creased prevalence rate and elevated frequency of HT antecedents.

\section{References}

[1] Williamson, S. and Greene, S.A. (2010) Incidence of Thyrotoxicosis in Childhood: A National Population Based Study in the UK and Ireland. Clinical Endocrinology (Oxf), 72, 358-363. http://dx.doi.org/10.1111/j.1365-2265.2009.03717.x

[2] Cooper, G.S. and Stroehla, B.C. (2003) The Epidemiology of Autoimmune Diseases. Autoimmunity Reviews, 2, 119125. http://dx.doi.org/10.1016/S1568-9972(03)00006-5

[3] Tozzoli, R. and Perini, R. (2007) Malattie autoimmuni nei primi anni di vita: dai sintomi alla diagnosi di laboratorio. La Rivista Italiana della Medicina di Laboratorio_Italian Journal of Laboratory Medicine, 3, 45-50.

[4] Hemminki, K., Li, X., Sundquist, J. and Sundquist, K. (2010) The Epidemiology of Graves' Disease: Evidence of a Genetic and an Environmental Contribution. Journal of Autoimmunity, 34, J307-313. http://dx.doi.org/10.1016/j.jaut.2009.11.019

[5] Larizza, D., Calcaterra, V. and Martinetti, M. (2009) Autoimmune stigmata in Turner syndrome: when lacks an X chromosome. Journal of Autoimmunity, 33, 25-30. http://dx.doi.org/10.1016/j.jaut.2009.03.002

[6] Bakalov, V.K., Gutin, L., Cheng, C.M., Zhou, J., Sheth, P., Shah, K., Arepalli, S., Vanderhoof, V., Nelson, L.M. and Bondy, C.A. (2012) Autoimmune Disorders in Women with Turner Syndrome and Women with Karyotypically Normal Primary Ovarian Insufficiency. Journal of Autoimmunity, 38, 315-321. http://dx.doi.org/10.1016/j.jaut.2012.01.015

[7] Lleo, A., Moroni, L., Caliari, L. and Invernizzi, P. (2012) Autoimmunity and Turner's Syndrome. Autoimmunity Reviews, 11, A538-543. http://dx.doi.org/10.1016/j.autrev.2011.11.015

[8] Livadas, S., Xekouki, P., Fouka, F., Kanaka-Gantenbein, C., Kaloumenou, I., Mavrou, A., Constantinidou, N. and Dacou-Voutetakis, C. (2005) Prevalence of Thyroid Dysfunction in Turner’s Syndrome: A Long-Term Follow-Up Study and Brief Literature Review. Thyroid, 15, 1061-1066. http://dx.doi.org/10.1089/thy.2005.15.1061

[9] Fukuda, I., Hizuka, N., Kurimoto, M., Morita, J., Tanaka, S., Yamakado, Y. and Takano, K. (2009) Autoimmune Thyroid Diseases in 65 Japanese Women with Turner Syndrome. Endocrine Journal, 56, 983-986. http://dx.doi.org/10.1507/endocrj.K09E-141

[10] Wasniewska, M., Corrias, A., Arrigo, T., Lombardo, F., Salerno, M., Mussa, A., Vigone, M.C. and De Luca, F. (2010) Frequency of Hashimoto's Thyroiditis Antecedents in the History of Children and Adolescents with Graves’ Disease. Hormone Research in Paediatrics, 73, 473-476. http://dx.doi.org/10.1159/000313395

[11] Valenzise, M., Aversa, T., Corrias, A., Mazzanti, L., Cappa, M., Ubertini, G., Scarano, E., Mussa, A., Messina, M.F., De Luca, F. and Wasniewska, M. (2014) Epidemiology, Presentation and Long-Term Evolution of Graves' Disease in Children, Adolescents and Young Adults with Turner Syndrome. Hormone Research in Paediatrics. (Epub ahead of print).

[12] Radetti, G., Mazzanti, L., Paganini, C., Bernasconi, S., Russo, G., Rigon, F. and Cacciari, E. (1995) Frequency, Clinical and Laboratory Features of Thyroiditis in Girls with Turner's Syndrome. The Italian Study Group for Turner's Syndrome. Acta Paediatrica, 84, 09-12.

[13] Invernizzi, P., Miozzo, M., Selmi, C., Persani, L., Battezzati, P.M., Zuin, M., Lucchi, S., Meroni, P.L., Marasini, B., Zeni, S., Watnik, M., Grati, F.R., Simoni, G., Gershwin, M.E. and Podda, M. (2005) X Chromosome Monosomy: A Common Mechanism for Autoimmune Diseases. Journal of Immunology, 175, 575-578. http://dx.doi.org/10.4049/jimmunol.175.1.575

[14] McGrogan, A., Seaman, H.E., Wright, J.W. and de Vries, C.S. (2008) The Incidence of Autoimmune Thyroid Disease: A Systematic Review of the Literature. Clinical Endocrinology (Oxf), 69, 687-696. http://dx.doi.org/10.1111/j.1365-2265.2008.03338.x

[15] El-Mansoury, M., Bryman, I., Berntorp, K., Hanson, C., Wilhelmsen, L. and Landin-Wilhelmsen, K. (2005) Hypothyroidism Is Common in Turner Syndrome: Results of a Five-Year Follow-Up. Journal of Clinical Endocrinology and Metabolism, 90, 2131-2135. http://dx.doi.org/10.1210/jc.2004-1262

[16] Gawlik, A., Gawlik, T., Januszek-Trzciakowska, A., Patel, H. and Malecka-Tendera, E. (2011) Incidence and Dynamics of Thyroid Dysfunction and Thyroid Autoimmunity in Girls with Turner's Syndrome: A Long-Term Follow-Up Study. Hormone Research in Paediatrics, 76, 314-320. http://dx.doi.org/10.1159/000331050

[17] de Kerdanet, M., Lucas, J., Lemee, F. and Lecornu, M. (1994) Turner’s Syndrome with X-Isochromosome and Hashimoto’s Thyroiditis. Clinical Endocrinology, 41, 673-676. http://dx.doi.org/10.1111/j.1365-2265.1994.tb01835.x

[18] Chiovato, L., Larizza, D., Bendinelli, G., Tonacchera, M., Marinó, M., Mammoli, C., Lorini, R., Severi, F. and Pinchera, A. (1996) Autoimmune Hypothyroidism and Hyperthyroidism in Patients with Turner's Syndrome. European Journal of Endocrinology, 134, 568-575. http://dx.doi.org/10.1530/eje.0.1340568

[19] Elsheikh, M., Wass, J.A. and Conway, G.S. (2001) Autoimmune Thyroid Syndrome in Women with Turner's Syn- 
drome-The Association with Karyotype. Clinical Endocrinology, 55, 223-226. http://dx.doi.org/10.1046/j.1365-2265.2001.01296.x

[20] Goldacre, M.J., Wotton, C.J., Scagroati, V. and Yeates, D. (2004) Cancers and Immune Related Diseases Associated with Down's Syndrome: A Record Linkage Study. Archives of Disease in Childhood, 89, 1014-1017. http://dx.doi.org/10.1136/adc.2003.046219

[21] Karlsson, B., Gustafsson, J., Hedov, G., Ivarsson, S.A. and Annerén, G. (1998) Thyroid Dysfunction in Down’s Syndrome: Relation to Age and Thyroid Autoimmunity. Archives of Disease in Childhood, 79, 242-245. http://dx.doi.org/10.1136/adc.79.3.242

[22] Castro Lobera, A. and Linares García-Valdecasas, R. (1999) A Thyroid Function Study in Subjects with Down’s Syndrome. Atencion Primaria, 23, 87-90.

[23] Gruñeiro de Papendieck, L., Chiesa, A., Bastida, M.G., Alonso, G., Finkielstain, G. and Heinrich, J.J. (2002) Thyroid Dysfunction and High Thyroid Stimulating Hormone Levels in Children with Down's Syndrome. Journal of Pediatric Endocrinology and Metabolism, 15, 1543-1548.

[24] Dias, V.M., Nunes, J.C., Araújo, S.S. and Goulart, E.M. (2005) Etiological Assessment of Hyperthyrotropinemia in Children with Down's Syndrome. Journal of Pediatrics, 81, 79-84. http://dx.doi.org/10.2223/JPED.1287

[25] Goday-Arno, A., Cerda-Esteva, M., Flores-Le-Roux, J.A., Chillaron-Jordan, J.J., Corretger, J.M. and Cano-Pérez, J.F. (2009) Hyperthyroidism in a Population with Down Syndrome (DS). Clinical Endocrinology, 71, 110-114.

[26] Jørgensen, K.T., Rostgaard, K., Bache, I., Biggar, R.J., Nielsen, N.M., Tommerup, N. and Frisch, M. (2010) Autoimmune Diseases in Women with Turner's Syndrome. Arthritis \& Rheumatism, 62, 658-666. http://dx.doi.org/10.1002/art.27270

[27] Gravholt, C.H., Hjerrild, B.E., Mosekilde, L., Hansen, T.K., Rasmussen, L.M., Frystyk, J., Flyvbjerg, A. and Christiansen, J.S. (2006) Body Composition Is Distinctly Altered in Turner Syndrome: Relations to Glucose Metabolism, Circulating Adipokines, and Endothelial Adhesion Molecules. European Journal of Endocrinology, 155, 583-592. http://dx.doi.org/10.1530/eje.1.02267

[28] Pellegrini, F.P., Marinoni, M., Frangione, V., Tedeschi, A., Gandini, V., Ciglia, F., Mortara, L., Accolla, R.S. and Nespoli, L. (2012) Down Syndrome, Autoimmunity and T Regulatory Cells. Clinical and Experimental Immunology, 169, 238-243. http://dx.doi.org/10.1111/j.1365-2249.2012.04610.x

[29] Ram, G. and Chinen, J. (2011) Infections and Immunodeficiency in Down Syndrome. Clinical and Experimental Immunology, 164, 9-16. http://dx.doi.org/10.1111/j.1365-2249.2011.04335.X

[30] Aversa, T., Lombardo, F., Corrias, A., Salerno, M., De Luca, F. and Wasniewska, M. (2014) In Young Patients with Turner or Down Syndrome, Graves’ Disease Presentation Is often Preceded by Hashimoto’s Thyroiditis. Thyroid, 24, 744-747. http://dx.doi.org/10.1089/thy.2013.0452

[31] Ludgate, M. and Emerson, C.H. (2008) Metamorphic Thyroid Autoimmunity. Thyroid, 18, 1035-1037. http://dx.doi.org/10.1089/thy.2008.1551

[32] Wasniewska, M., Corrias, A., Messina, M.F., Crisafulli, G., Salzano, G., Valenzise, M., Mussa, A. and De Luca, F. (2010) Graves' Disease Prevalence in a Young Population with Turner Syndrome. Journal of Endocrinological Investigation, 33, 69-70. http://dx.doi.org/10.1007/BF03346552

[33] Troisi, A., Novati, P., Sali, L., Colzani, M., Monti, G., Cardillo, C. and Tesauro, M. (2013) Graves’ Thyrotoxicosis Following Hashimoto's Thyroiditis. Research and Reports in Endocrine Disorders, 3, 13-15.

[34] De Luca, F., Corrias, A., Salerno, M., Wasniewska, M., Gastaldi, R., Cassio, A., Mussa, A., Aversa, T., Radetti, G. and Arrigo, T. (2010) Peculiarities of Graves' Disease in Children and Adolescents with Down's Syndrome. European Journal of Endocrinology, 162, 591-595. http://dx.doi.org/10.1530/EJE-09-0751

[35] Salzano, G., Lombardo, F., Arrigo, T., Sferlazzas, C., Wasniewska, M., Valenzise, M. and De Luca, F. (2010) Association of Five Autoimmune Diseases in a Young Woman with Down's Syndrome. Journal of Endocrinological Investigation, 33, 202-203. http://dx.doi.org/10.1007/BF03346582 
Scientific Research Publishing (SCIRP) is one of the largest Open Access journal publishers. It is currently publishing more than 200 open access, online, peer-reviewed journals covering a wide range of academic disciplines. SCIRP serves the worldwide academic communities and contributes to the progress and application of science with its publication.

Other selected journals from SCIRP are listed as below. Submit your manuscript to us via either submit@scirp.org or Online Submission Portal.
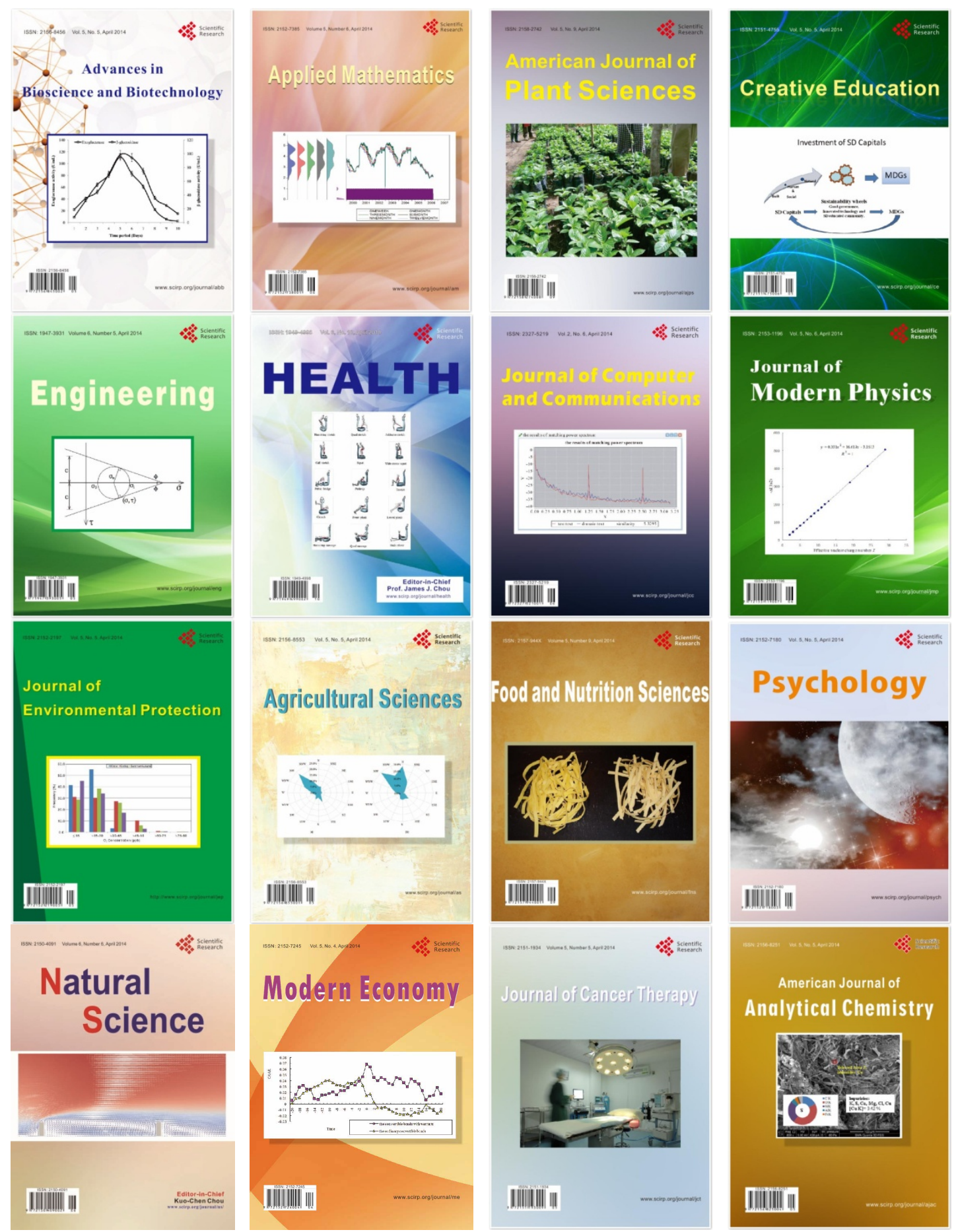